\title{
Sistema Web para Controle dos Pedidos de Reservas de Recursos em Instituições de Ensino Superior
}

\author{
Tiego A. do Nascimento ${ }^{1}$, Eyder Franco Sousa Rios ${ }^{1}$, Rodrigo A. R. S. Baluz ${ }^{1}$ \\ ${ }^{1}$ Bacharelado em Ciência da Computação. \\ Universidade Estadual do Piauí - Parnaíba, PI - Brasil. \\ tiegonasc@gmail.com, \{eyder, rodrigo.baluz\}@phb.uespi.br
}

Abstract. The computerization process is a way to connect public and private institutions with advances in technology and innovation. Out of this concept, Brazilian public universities suffer from the lack of initiatives that make this connection possible. This paper proposes using an online platform for the administrative management of physical resource reserves of a public university in the state of Piauí. For this, a web system was developed based on requirements achieved from interviews with the administration of one campus in this institution. After testing, the system usability was measured based on the System Usability Scale, obtaining an excellent acceptance rate.

Resumo. O processo de informatização é uma forma de conectar instituições públicas e privadas com os avanços da tecnologia e inovação. Fugindo desse conceito, as universidades públicas brasileiras sofrem com a falta de iniciativas que possibilitam essa conexão. Esse trabalho propõe o uso de uma plataforma online para a gestão administrativa das reservas de recursos físicos de uma universidade pública do estado do Piauí. Para isso, um sistema web foi desenvolvido com base em requisitos levantados a partir de entrevistas com a administração de um dos câmpus desta instituição. Após testes realizados, a usabilidade do sistema foi mensurada com base na Escala de Usabilidade do Sistema, obtendo um excelente índice de aceitação.

\section{Introdução}

As universidades, assim como várias organizações públicas brasileiras, têm sofrido com a morosidade nos processos administrativos [Janissek et al. 2017]. As barreiras burocráticas impostas pela legislação em entidades públicas, assim como gestões abertas para novos processos, contribuem para o atraso no avanço da inovação [Vieira, E. e Vieira, M. 2004]. A valorização de iniciativas inovadoras no setor público é um caminho para a melhoria do cenário, conforme visto em Camões, Severo e Cavalcante (2017) e Digix (2018). Para Vieira, E. e Vieira, M. (2004), protelar iniciativas inovadoras no ambiente universitário pode levar estas instituições a um passado cada vez mais distante dos padrões exigidos atualmente pela sociedade. 
Espaços, recursos e serviços de instituições públicas de ensino estão disponíveis, sob a forma da lei, à comunidade acadêmica (alunos e professores) e à comunidade em geral. O art. 22 da Lei Federal 9.636/98 - regulamentado pelo art. 14 do Decreto $3.725 / 2001$, possibilita que o poder público autorize, pela permissão de uso, a utilização de áreas de domínio da União, a título precário, para a realização de eventos de curta duração, de natureza recreativa, esportiva, cultural, religiosa ou educacional. Entretanto, as instituições de ensino superior geralmente não possuem um sistema público e transparente que permita o acesso facilitado para reservas de seus recursos. Para a gestão administrativa destas instituições falta um gerenciamento maio dos seus recursos disponíveis, o que na maioria das vezes leva a uma subutilização dos espaços e serviços.

O objetivo desse trabalho é apresentar uma alternativa informatizada e inovadora para auxiliar na gestão administrativa das reservas de recursos físicos de uma instituição de ensino superior. Foi usado como campo para desenvolvimento do estudo a Universidade Estadual do Piauí, campus Professor Alexandre Alves de Oliveira, em Parnaíba (UESPI-Parnaíba). Atualmente as reservas dos espaços, equipamentos e transportes são feitas de forma manual pelos servidores e, após, registradas na ferramenta Google Calendar da instituição. A demanda de reservas para uso desses recursos é alta e frequentemente causa sobrecarrega de trabalho.

A plataforma de reservas online foi produzida com o auxílio de ferramentas que são usuais em pequenos, médios e grandes projetos de software. Seu desenvolvimento se deu pelo uso do modelo de prototipação, em que um produto inicial foi criado com base em requisitos iniciais levantados pelos próprios autores e melhorado a partir da adição de novos requisitos obtidos em reuniões com a direção da UESPI-Parnaíba. Testes foram realizados com usuários da própria instituição e, ao fim, um questionário aplicado avaliou o nível de satisfação dos usuários com a plataforma. O sistema contempla funcionalidades que facilitam e automatizam o processo de reserva dos recursos da UESPI-Parnaíba, e ainda conta com uma interface fácil de ser entendida, dispensando a necessidade de conhecimento técnico para usá-lo. Os resultados do trabalho mostram que a satisfação com a utilização desse sistema é positiva e que o seu uso pode contribuir com a gestão administrativa do campus.

O presente artigo está dividido em 5 seções, sendo esta primeira a introdução. Após, a seção 2 apresenta os trabalhos relacionados, cujos objetivos são desenvolvimento de sistemas para instituições públicas de ensino. A seção 3 discorre sobre a metodologia adotada e sua execução. Na seção 4 é exposto o resultado de desenvolvimento da plataforma e o resultado da aplicação do questionário que buscou medir a sua usabilidade. Por fim, na seção 5 são feitas as considerações finais.

\section{Trabalhos relacionados}

Trabalhos que relatam o uso de sistemas informatizados para melhorar a qualidade dos serviços nas universidades públicas podem ser encontrados na literatura, mesmo que 
escassos. Estes são geralmente apresentados à sociedade como monografias de cursos ligados à tecnologia. Nos parágrafos a seguir, estão descritos exemplos de sistemas informatizados desenvolvidos para universidades públicas com ênfase nas justificativas e resultados.

Cunha et al. (2017) elaboraram um sistema web que automatizou a solicitação de trancamento de disciplinas ou matrícula no curso de Análise e Desenvolvimento de Sistemas na Faculdade de Tecnologia (FATEC) de Carapicuíba. Os autores relatam que o antigo processo de trancamento era ineficiente, feito todo em papel, onde as justificativas dos alunos eram escritas em texto livre. O sistema elaborado fornece aos gestores a rastreabilidade das solicitações de trancamento, elimina os inconvenientes devidos a perda de documentos e considera a ideia benéfica à sustentabilidade, pois não haveria papéis impressos.

O trabalho de Paulino (2017) focou na análise do processo de adoção do Sistema Eletrônico de Informação (SEI) na Universidade de Brasília. Trata-se de uma plataforma que engloba um conjunto de módulos e funcionalidades que promovem a eficiência administrativa. O objetivo geral do trabalho foi descrever como ocorreu a adoção do SEI na UnB, identificando os principais fatores facilitadores e dificultadores. Os principais benefícios identificados após a adoção do SEI foram a melhoria na rotina de trabalho e o aumento da transparência na tramitação dos processos. Além disso, entrevistados destacaram como um dos principais benefícios a redução dos custos com papel.

Oliveira (2018) desenvolveu um sistema web para a gestão das salas do Centro Interdisciplinar de Novas Tecnologias na Educação, setor da Universidade Federal do Rio Grande do Sul. A instituição encontrava entraves na forma de agendamentos, pois eram feitos em planilhas e não possuíam nenhuma forma de controle automático sobre os horários das salas, a não ser o cuidado dos próprios usuários e funcionários no momento da marcação dos horários. O sistema criado foi baseado em uma implementação já existente e em requisitos coletados no local específico onde foi aplicado. Os testes realizados demonstraram que o sistema conseguiu atingir seu objetivo de ser simples e efetivo, mantendo o fluxo o mais direto possível e executando as tarefas esperadas. Além disso, uma avaliação pós-teste feita com os usuários demonstrou a aprovação do uso desse sistema.

Funchal (2011) desenvolveu um sistema web para reserva dos recursos de um departamento de uma universidade não citada no trabalho. Segundo o próprio autor, o sistema proporciona um maior controle das reservas de modo a facilitar o trabalho tanto dos responsáveis pelo departamento quanto dos usuários (professores e técnicos administrativos). A reserva de recursos feita de forma manual requer muita atenção e torna-se complexo controlar diversas requisições quando a há um aumento na demanda por reservas. Justifica ainda que a utilização desta ferramenta computacional elimina a 
necessidade de se usar papel no processo de reservas e possibilita que a gerência das informações seja mais dinâmica e eficaz.

\section{Métodos e Técnicas}

Este trabalho se caracteriza por uma pesquisa descritiva, onde foram considerados uma análise minuciosa e descritiva do objeto de estudo. O método usado para a investigação aprofundado do problema em questão, considerando o contexto de sua aplicação, foi o estudo de caso junto a uma instituição de ensino superior pública. Para desenvolvimento do estudo de caso foram necessárias a realização de entrevistas e análise documental para elucidação dos requisitos necessários para desenvolvimento da plataforma web. A análise dos dados considerou uma abordagem quali-quantitativa, a partir da aplicação de um questionário da experiência do usuário com a proposta.

Esta seção irá desenvolver os passos assumidos durante o desenvolvimento da pesquisa, desde definição de seu modelo de software para o projeto, a elucidação dos requisitos funcionais para a aplicação partindo de reuniões mantidas com a administração superior, professores e alunos, modelos lógicos para as funcionalidades e interações do sistema, além da escolha das ferramentas de desenvolvimento com base em produtividade e portabilidade.

\subsection{Modelo de software}

Segundo Sommerville (2011), a prototipação é um modelo em que uma versão do sistema ou de parte dele é rapidamente desenvolvida para seja possível verificar as necessidades do cliente e saber se algumas decisões de projeto são viáveis, e complementa definindo um protótipo como uma versão inicial de um software, usado para demonstração de conceitos, testar opções de projeto e se aprofundar mais sobre o problema e suas possíveis soluções. O modelo de desenvolvimento de software aplicado neste trabalho foi o Modelo de Prototipação, conforme a Figura 1. 


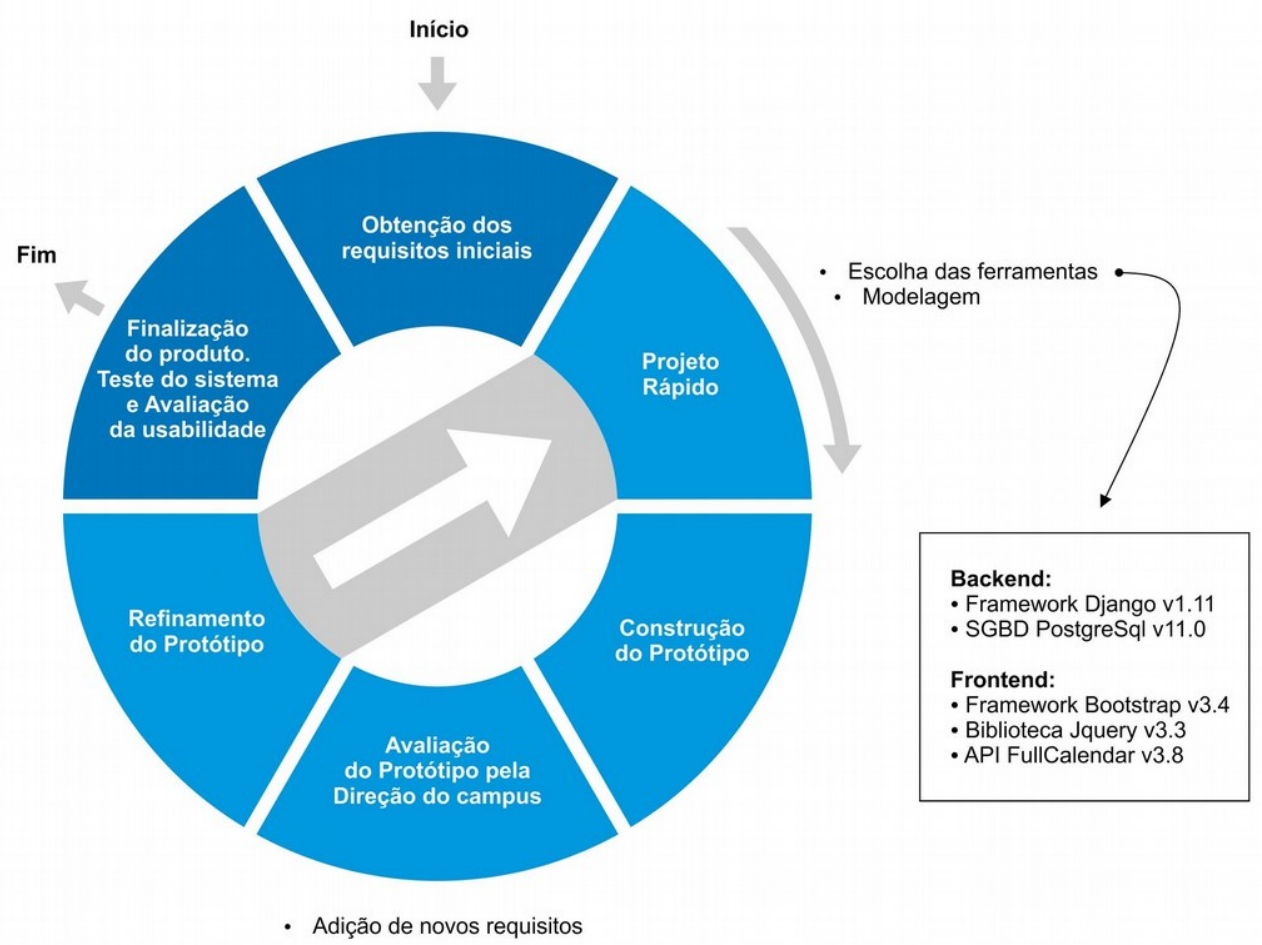

Figura 1. Modelo de desenvolvimento do sistema.

\subsection{Requisitos do sistema}

Durante o processo inicial de desenvolvimento desse software foi construído um produto mínimo viável (Minimum Viable Product - MVP) baseado em requisitos iniciais, em que foram considerados os diferentes tipos de usuários que podem ser cadastrados, os diferentes tipos de recursos que podem ser disponibilizados, regras básicas para criação de pedidos de reserva e o papel dos administradores do sistema. $\mathrm{O}$ MVP desenvolvido foi apresentado à direção da UESPI-Parnaíba que, após análise, sugeriu melhorias e adição de novos requisitos. Os principais requisitos que caracterizam o sistema de reserva desenvolvido estão listados de forma resumida a seguir.

- O sistema deve compreender diferentes tipos de usuários, cada tipo com diferentes permissões relacionadas;

- Os recursos deverão ser categorizados por diferentes tipos, sendo os principais "Espaço", "Equipamento" e "Transporte";

- Todo pedido deve ter um status, podendo este ser "Em Análise”, “Aceito", "Negado" ou "Cancelado";

- Todo o controle dos recursos (adição, edição, ativação e desativação) será de responsabilidade da administração;

- Os usuários serão cadastrados, ativados ou desativados exclusivamente pela administração; 
- O acesso ao sistema deverá ser exclusivo para usuários cadastrados e ativos;

- Para reservar determinados recursos será necessária a avaliação da direção do campus. A administração terá as opções de aceitar ou negar os pedidos que contenham pelo menos um recurso com esta restrição;

- Para reservar determinados recursos será necessária, além da avaliação da administração, a anexação de um documento ofício;

- Todo usuário poderá cancelar qualquer pedido de reserva realizado por si a qualquer momento;

- Usuários deverão ser notificados imediatamente após seus pedidos serem avaliados pela administração.

\subsection{Modelagem do sistema}

Em posse dos requisitos, se deu início ao projeto inicial que serviu para abstração e orientação para o desenvolvimento do sistema. O projeto de software foi construído principalmente por meio do uso de diagramas baseados em notações da Linguagem de Modelagem Unificada (Unified Modeling Language - UML) [Sommerville 2011].

A modelagem iniciou-se com a criação do diagrama de Casos de Uso. Os diagramas de Casos de Uso são bastante simples e ajudam a entender as funcionalidades do software, abrangendo uma visão estática das situações de interação dos atores com o sistema sem se aprofundar em detalhes técnicos [Booch, Rumbaugh e Jacobson 2005].

A Figura 2 mostra os Casos de Uso para um usuário comum, ou seja, aquele que solicita a reserva. É importante frisar que, conforme os requisitos, podem existir diversos tipos de usuários diferentes no sistema, como Professor, Coordenador de Curso, Técnico Administrativo, e outros, cada tipo com suas determinadas permissões. Portanto, o diagrama da Figura 2 representa, de forma geral, os Casos de Uso pertencentes a qualquer tipo de usuário, inclusive os próprios Administradores.

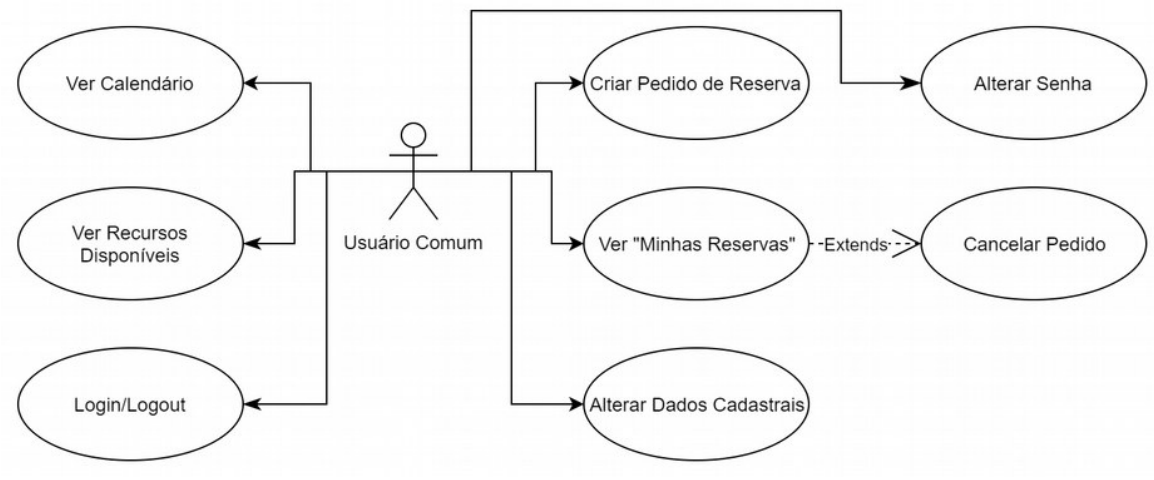

Figura 2. Casos de Uso do usuário comum.

Já no diagrama da Figura 3, um administrador do sistema pode desempenhar diversas outras funções, além das mesmas funções de um usuário comum. Dentre as 
principais ações estão a de avaliar um pedido, representada pelo Caso de Uso "Aceitar/ Negar Pedido"; configurar o Campus, descrita no Casos de Uso "Adicionar/Editar, Ativar/Desativar Unidade"; fazer o controle de cadastro dos usuários, representada por "Cadastrar, Ativar/Desativar Usuário"; e gerenciar os recursos cadastrados no sistema, representada por "Adicionar/Editar, Ativar/Desativar Recurso".

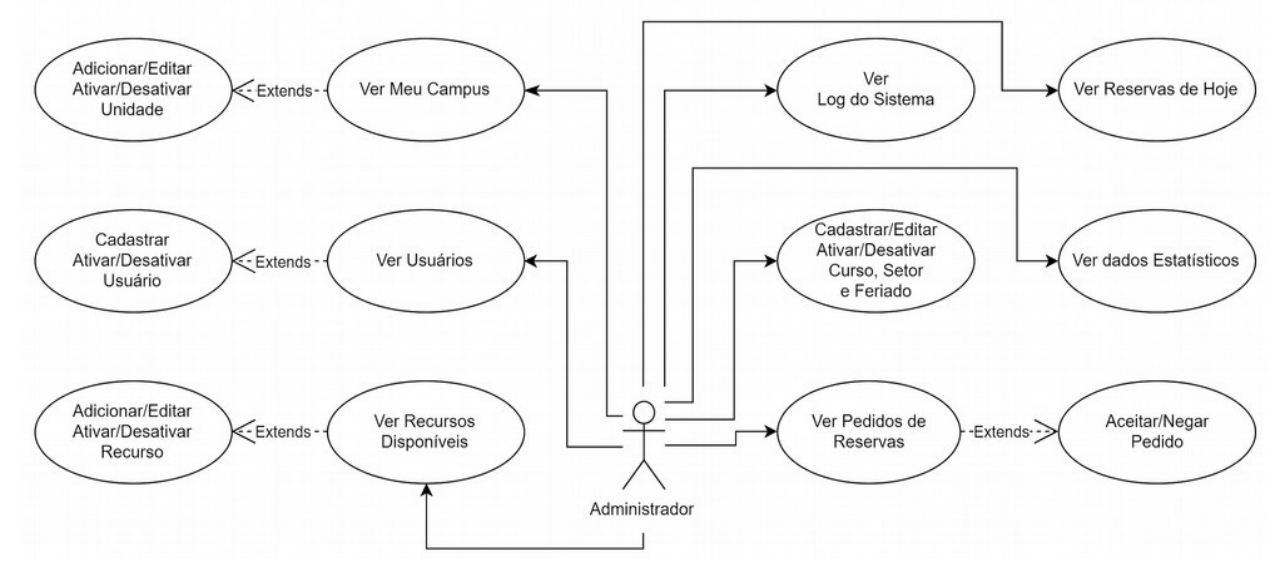

Figura 3. Casos de Uso específicos do usuário administrador.

O Diagrama de Classes da Figura 4 apresenta as principais classes do sistema e suas relações. $\mathrm{O}$ intuito da criação desse diagrama é meramente mostrar a organização das classes. No framework Django, que será citado na subseção 3.4, todos os modelos do banco de dados são criados a partir de classes, e estas, sempre derivam de uma classe pai chamada "Models", a qual não foi representada no diagrama por motivos de organização. Portanto, todas as classes apresentadas no diagrama estão intrinsecamente ligadas ao banco de dados. E em respeito a completa estrutura de classes oferecida pelo framework usado, também não se fez necessário criar métodos como "registrarNovo" ou "editarDados", pois estas são operações feitas por meio da instanciação da classe. Existem ainda diversos métodos e atributos derivados da classe "Models" que não estão representados no digrama. Todos os detalhes dos métodos derivados da classe "Models" podem ser encontrados na documentação do framework Django [Django 2017]. 


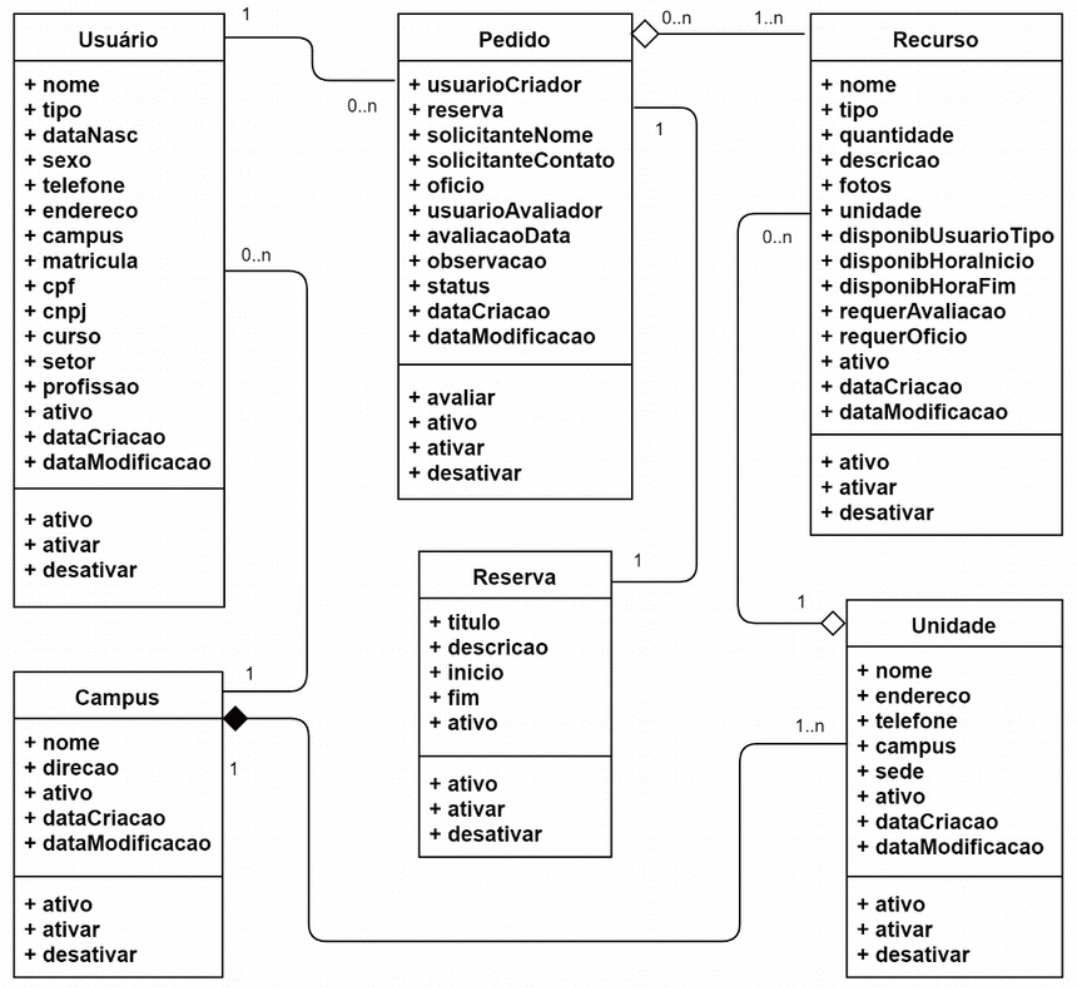

Figura 4. Diagrama de Classes.

Como pode ser observado na Figura 4, a classe "Usuario" representa os usuários do sistema, que podem ser de tipos diferentes, cada tipo com suas próprias permissões de ação dentro do sistema. Um "Pedido" deve obrigatoriamente conter ao menos 1 "Recurso" para ser reservado. Um "Recurso" pertence a uma "Unidade", ou seja, cada unidade do campus tem seus próprios recursos. Um "Campus" é sempre constituído de uma "Unidade" sede, podendo ter mais unidades não sedes. A classe "Reserva" serve unicamente para facilitar a exibição das reservas nas telas de calendário.

\subsection{Escolha das ferramentas}

Após a criação dos modelos, foram escolhidas as ferramentas para o desenvolvimento do sistema. As ferramentas deste projeto se destacam pela produtividade e por serem recorrentemente usadas em projetos de software voltados para web, sendo elas:

- Framework Django, na sua versão 1.11;

- SGBD PostgreSql, na versão 11;

- Framework de estilização Bootstrap v3.4;

- Biblioteca de Javascript Jquery v3.3; e,

- API Fullcalendar v3.8, utilizada para a geração de calendários dinâmicos. 


\section{Resultados e Discussão}

O resultado desse trabalho é constituído pela plataforma de reservas desenvolvida e principalmente pela avaliação dos usuários quanto a sua usabilidade. As subseções seguintes detalham os resultados obtidos.

\subsection{O sistema desenvolvido}

A Figura 5 mostra a tela principal do sistema sob a perspectiva de um professor, aqui denominado "Alan Turing". Trata-se do painel do usuário, onde estão organizadas as principais opções de interação com o sistema, de acordo com as permissões estabelecidas para cada tipo de usuário.

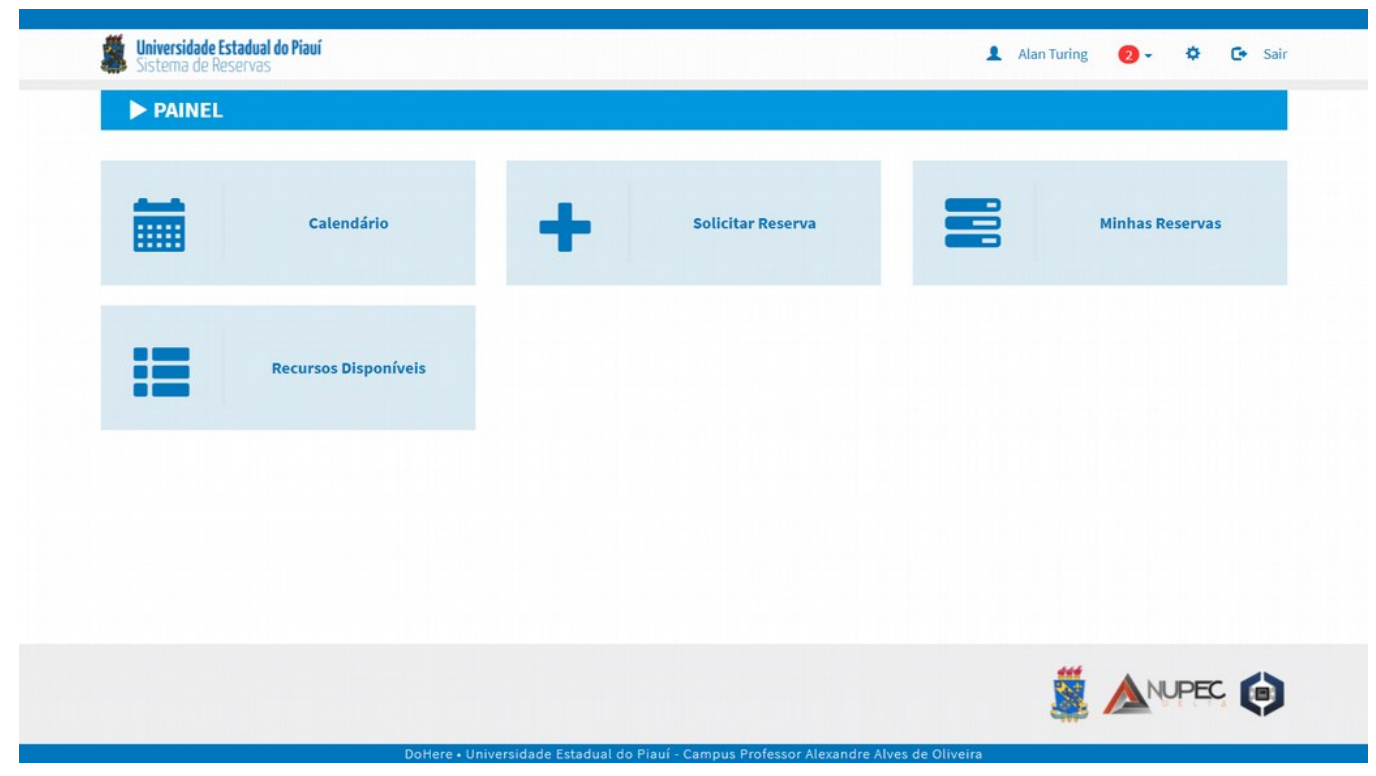

Figura 5. Painel do Usuário.

A opção "Calendário" mostra o calendário de reservas da instituição, onde estão dispostos os horários dos pedidos com status "Aceito" realizados por todos os usuários. Já a opção "Solicitar Reserva" possibilita a criação de um pedido de reserva por meio de uma série de etapas, conforme o digrama de atividades apresentado na Figura 6.

Ao fim de todo o processo, o pedido então é realizado e uma notificação é enviada para todos os administradores. Existem 2 tipos de notificação que podem ser gerados: a notificação de sistema, que aparece no cabeçalho da plataforma; e a notificação por $e$-mail, que são enviados para os usuários em atividades com maior grau de importância. Administradores da plataforma podem desempenhar diversas outras funções dentro do sistema, portanto, existem outras opções no seu painel, além das mesmas contidas no Painel do Usuário (Figura 5). São elas: "Reservas do dia", "Pedidos de Reserva", "Usuários", "Meu Campus", "Outros Cadastros" e "Estatísticas". A gerência dos recursos é feita na opção "Recursos Disponíveis", a mesma do Painel do Usuário, porém, sem restrição de acesso para adição e edição dos recursos. 


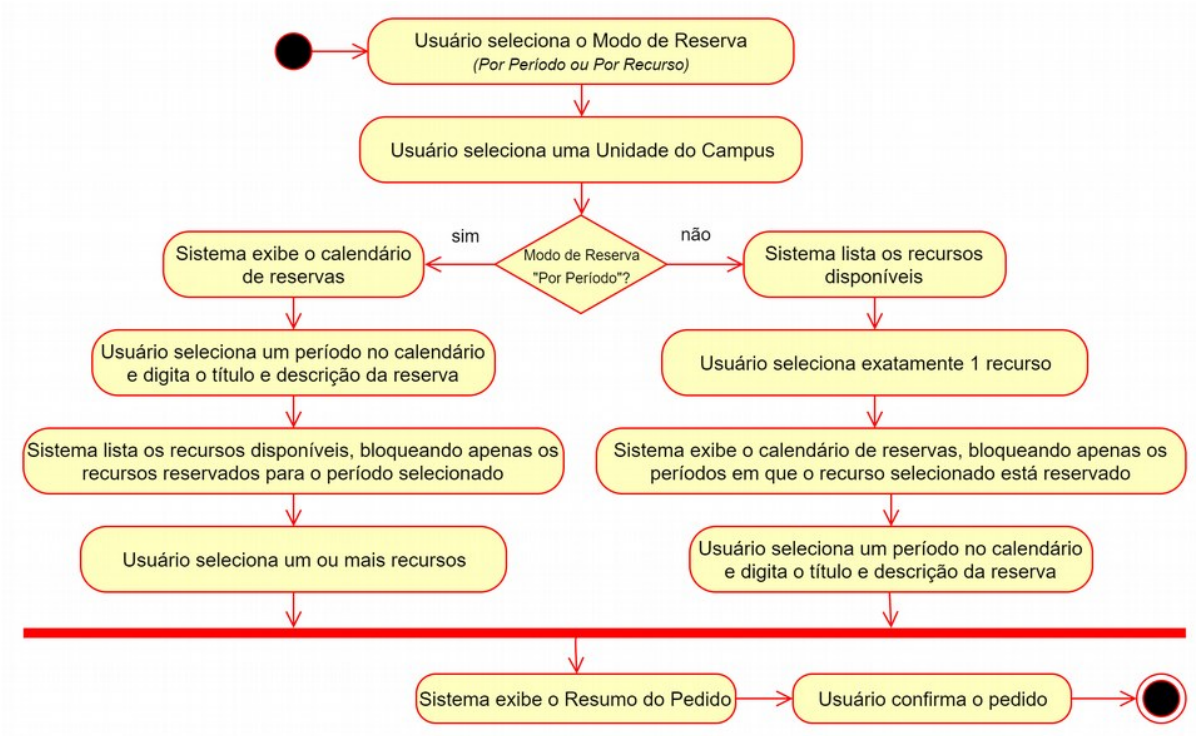

Figura 6. Diagrama de atividades. Processo de solicitação de reservas.

Na opção "Pedidos de Reserva", o administrador tem acesso a todos os pedidos realizados. A Figura 7 mostra um exemplo da lista de pedidos realizados.

\begin{tabular}{|c|c|c|c|c|c|}
\hline Data/Hora & Titulo & Usuário & Tipo do Ustánio & status & Avaliado em \\
\hline $22 / 06 / 19-22: 53$ & Computaçăo - Reserva do micro-ônibus & & Coordenador & Em Análise & $-1-1-$ \\
\hline $22 / 06 / 19-22: 44$ & Reserva do auditório central. & & Coordenador & aceito & $23 / 06 / 19-10: 20$ \\
\hline $22 / 06 / 19-22: 34$ & Reserva do projetor multimídia & & Coordenador & aceito & 22/06/19-22:34 \\
\hline 19/06/19-10:03 & Viagem a Teresina & & Técnico Administrativo & a Aceito & $23 / 06 / 19-10: 18$ \\
\hline $16 / 06 / 19-16: 36$ & Palestra Curso Biologia & & Professor & Aceito & $17 / 06 / 19-08: 34$ \\
\hline $15 / 06 / 19-07: 39$ & MANUTENÇÃO DE EQUIPAMENTOS & & Técnico Administrativo & aceito & 15/06/19-11:39 \\
\hline $15 / 06 / 19-07: 37$ & RESERVA & & Técnico Administrativo & aceito & $15 / 06 / 19-07: 37$ \\
\hline $15 / 06 / 19-07: 29$ & Ensaio Colaçăo de Grau & & Técnico Administrativo & aceito & 15/06/19-11:09 \\
\hline $15 / 06 / 19-07: 21$ & Aula & & Coordenador & - Cancelado & $-1-1$ \\
\hline 15/06/19-07:14 & Aula & & Coordenador & - Aceito & $15 / 06 / 19-11: 10$ \\
\hline 14/06/19-14:06 & Ensaio Colaçăo de Grau & & Técnico Administrativo & - Negado & $15 / 06 / 19-01: 33$ \\
\hline $14 / 06 / 19-06: 22$ & Reuniăo para viagem & & Professor & - Cancelado & $-1-1-$ \\
\hline $11 / 06 / 19-13: 38$ & Assembleia de Eleiçăo do CATI & & Professor & - Cancelado & $-1-1$ \\
\hline $11 / 06 / 19-05: 10$ & Aula de Introdução à arqueologia & & Professor & aceito & $11 / 06 / 19-05: 10$ \\
\hline $06 / 06 / 19-22: 31$ & Aula de Genética & & Professor & aceito & $06 / 06 / 19-22: 31$ \\
\hline 05/06/19-12:20 & Aula de História da América & & Portaria & - Aceito & $05 / 06 / 19-12: 20$ \\
\hline $05 / 06 / 19-10: 20$ & Aula de Geoprocessamento & & Coordenador & aceito & 05/06/19-10:20 \\
\hline $05 / 06 / 19-08: 53$ & Matrículas $6^{\circ}$ Convocaçăo do SISU & & Técnico Administrativo & aceito & $05 / 06 / 19-08: 53$ \\
\hline $09 / 05 / 19-12: 11$ & Aula de campo no DITALPI & & Administrador & aceito & $09 / 05 / 19-12: 11$ \\
\hline
\end{tabular}

Figura 7. Recorte da página "Pedidos de Reserva".

Na coluna "Usuário" os nomes dos usuários foram ocultados para que suas identidades fossem preservadas. Para avaliar um pedido, o administrador deve clicar em um item da lista de pedidos, e, a partir de então, é mostrada a tela ilustrada na Figura 8. Esta tela pode ser acessada apenas por administradores e por tipos de usuário que tenham permissão para avaliar pedidos, que é o caso do tipo de usuário "Secretaria". Nesta tela, o avaliador pode visualizar e analisar todos os detalhes referentes a um determinado pedido e, a partir de então, pode escolher entre "Aceitar" ou "Negar" o pedido. Após concluir a avaliação, uma notificação de sistema é enviada ao usuário que fez o pedido e, também, uma mensagem de e-mail notificando-o que o seu pedido foi avaliado. 


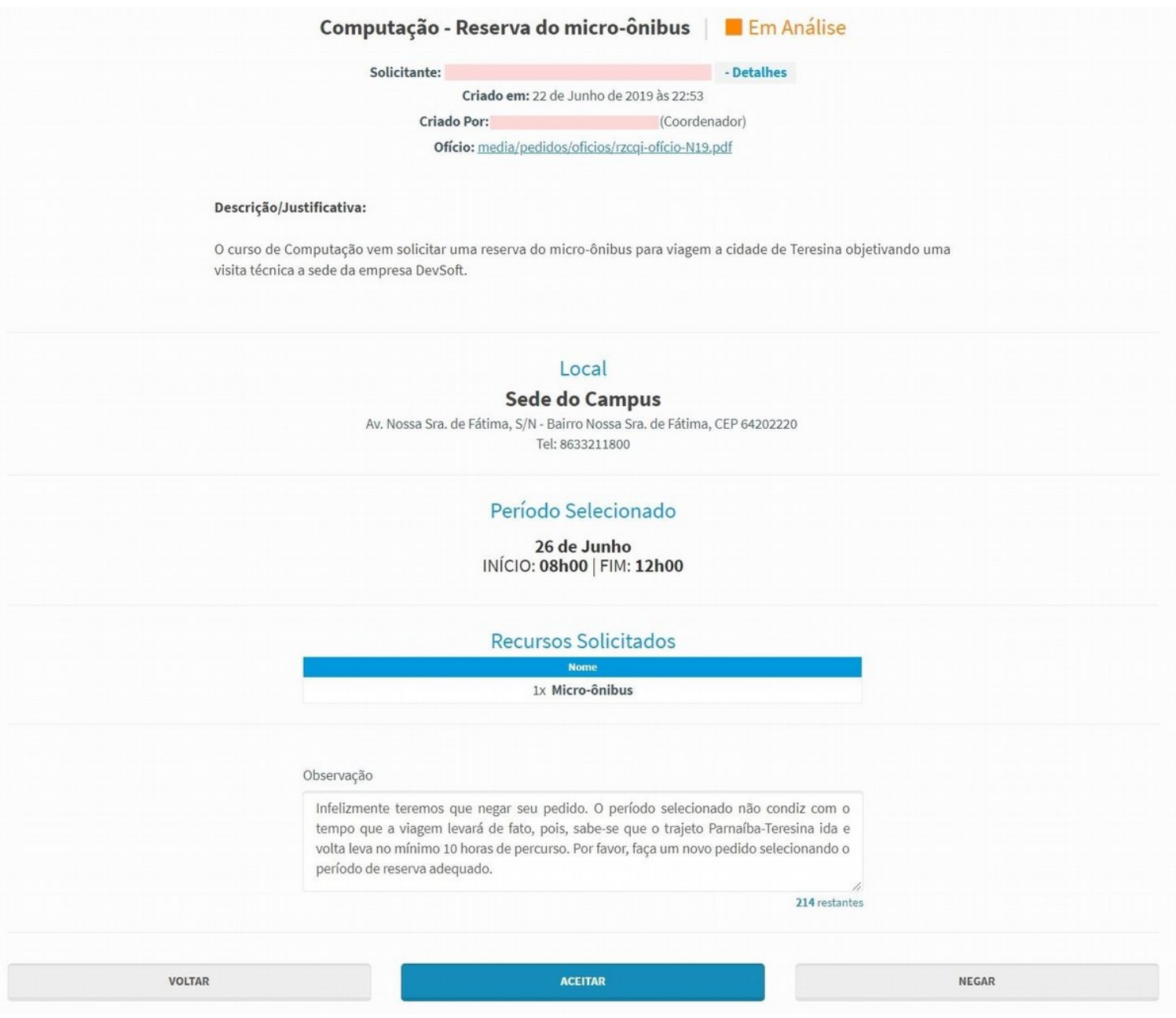

Figura 8. Recorte da página "Pedido de Reserva".

Assim como os usuários comuns, o administrador também pode "Solicitar Reserva", tendo como diferença a dispensa das exigências de avaliação do pedido. Além disso, todos os pedidos realizados são aceitos de imediato e de forma automática, pois não há necessidade de avaliação, já que quem estaria realizando a reserva seria o mesmo responsável por avaliar.

A plataforma desenvolvida possui diversas outras telas que ajudam na gestão dos recursos, usuários, reservas, unidades do campus, dados cadastrais, registros de log, suporte para alteração e recuperação de senha, entre outras funcionalidades.

\subsection{Avaliação e validação do sistema}

Foram convidados 10 usuários para testar o sistema, sendo eles 1 diretor, 1 secretária, 1 funcionário da portaria, 2 coordenadores de curso, 3 professores e 2 técnicos administrativos. Antes de serem cadastrados no sistema, os convidados passaram por um breve treinamento de 60 minutos, onde foram ensinados os procedimentos básicos para criar pedidos de reserva, consultar o calendário de reservas do campus, visualizar 
os recursos disponíveis e cancelar um pedido de reserva. A relação dos usuários convidados pode ser vista na Tabela 1. Após o treinamento, os usuários foram cadastrados na plataforma com seus dados pessoais reais. Foi elaborada uma série de tarefas abrangendo todas as funcionalidades do sistema para que os usuários, durante 30 dias, pudessem realizá-las.

Tabela 1. Relação de convidados que participaram dos testes da plataforma.

\begin{tabular}{|c|c|}
\hline Convidados & Tipo de Usuário \\
\hline Convidado 1 & Administrador \\
\hline Convidado 2 & Secretaria \\
\hline Convidado 3 & Portaria \\
\hline Convidado 4 & Coordenador de Curso \\
\hline Convidado 5 & Coordenador de Curso \\
\hline Convidado 6 & Professor \\
\hline Convidado 7 & Professor \\
\hline Convidado 8 & Professor \\
\hline Convidado 9 & Técnico Administrativo \\
\hline Convidado 10 & Técnico Administrativo \\
\hline
\end{tabular}

Uma forma de se medir a usabilidade de um sistema é apresentada por Brooke (1995), trata-se de um questionário denominado Escala de Usabilidade do Sistema (System Usability Scale - SUS) que pode ser aplicado para avaliar a usabilidade de produtos, serviços e aplicações. Essa metodologia já foi referenciada em mais de 600 publicações e é considerada um padrão industrial na medição da usabilidade, estando definida no ISO 9241-11 [Sauro 2011].

Para a avaliação da usabilidade do sistema aqui criado, foi elaborado um questionário com as 10 primeiras questões baseadas no SUS, que foram adaptadas de Sauro (2011) e Brooke (1995) por Teixeira, F. (2016), e outras 2 questões, criadas pelos próprios autores, relativas ao contexto de funcionalidade do sistema na UESPI-Parnaíba, totalizando 12 questões. As questões estão enumeradas a seguir.

1. Eu acho que gostaria de usar esse sistema com frequência.

2. Eu acho o sistema desnecessariamente complexo.

3. Eu achei o sistema fácil de usar.

4. Eu acho que precisaria de ajuda de uma pessoa com conhecimentos técnicos para usar o sistema.

5. Eu acho que as várias funções do sistema estão muito bem integradas. 
6. Eu acho que o sistema apresenta muita inconsistência.

7. Eu imagino que as pessoas aprenderão como usar esse sistema rapidamente.

8. Eu achei o sistema atrapalhado de usar.

9. Eu me senti confiante ao usar o sistema.

10. Eu precisei aprender várias coisas novas antes de conseguir usar o sistema.

11. Eu usaria a plataforma caso fosse implantada no campus.

12. Eu acredito que a plataforma pode contribuir com a gestão administrativa do campus.

Com respeito à metodologia SUS, para cada questão os respondentes puderam escolher uma das opções de resposta dispostas na Figura 9. As opções de resposta criadas foram formuladas com base nas diretrizes de Sauro (2011) e Brooke (1995).

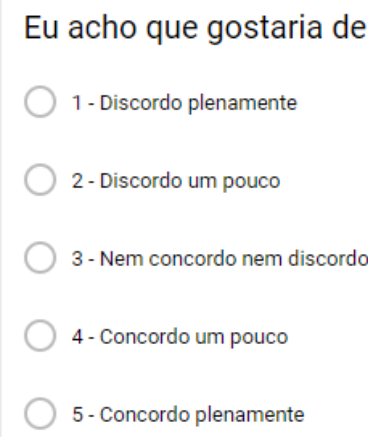

Figura 9. Exemplo de questão, de acordo com a metodologia do SUS.

Cada opção de resposta tem um valor referente a uma pontuação. Esses valores são usados para calcular o score final do SUS [Sauro 2011; Brooke 1995]. O questionário foi aplicado online através da ferramenta Formulários Google logo após o fim do período de testes. A Tabela 2 lista as respostas obtidas com os sujeitos da pesquisa. A primeira coluna refere-se à ordem dos respondentes do questionário. $\mathrm{O}$ termo Q1 presente no cabeçalho da segunda coluna representa "Questão 1" e se refere ao item 1 do questionário presente na subseção 3.7 deste artigo. $\mathrm{O}$ raciocínio segue o mesmo para o restante do cabeçalho.

Tabela 2. Respostas obtidas no questionário.

\begin{tabular}{|c|c|c|c|c|c|c|c|c|c|c|}
\hline Respondentes & Q1 & Q2 & Q3 & Q4 & Q5 & Q6 & Q7 & Q8 & Q9 & Q10 \\
\hline R1 & 5 & 2 & 4 & 1 & 4 & 2 & 5 & 1 & 5 & 1 \\
\hline R2 & 5 & 1 & 5 & 1 & 5 & 1 & 5 & 1 & 5 & 1 \\
\hline R3 & 5 & 3 & 4 & 1 & 5 & 1 & 5 & 1 & 5 & 1 \\
\hline R4 & 5 & 2 & 5 & 1 & 5 & 1 & 4 & 1 & 5 & 1 \\
\hline R5 & 1 & 2 & 5 & 1 & 4 & 2 & 2 & 1 & 5 & 1 \\
\hline R6 & 5 & 1 & 5 & 1 & 5 & 1 & 5 & 1 & 5 & 1 \\
\hline
\end{tabular}




\begin{tabular}{|c|c|c|c|c|c|c|c|c|c|c|}
\hline R7 & 5 & 1 & 5 & 1 & 4 & 1 & 5 & 1 & 5 & 1 \\
\hline $\mathrm{R} 8$ & 5 & 1 & 5 & 1 & 5 & 1 & 5 & 1 & 5 & 1 \\
\hline $\mathrm{R} 9$ & 5 & 1 & 5 & 1 & 5 & 1 & 5 & 1 & 5 & 1 \\
\hline $\mathrm{R} 10$ & 5 & 1 & 5 & 1 & 4 & 1 & 5 & 1 & 5 & 1 \\
\hline
\end{tabular}

De acordo com a metodologia SUS explicada por Sauro (2011), para o cálculo do score final devem ser seguidos os passos:

1. Para as questões ímpares, subtraia 1 da pontuação que o usuário respondeu.

2. Para as questões pares, subtraia a pontuação da resposta do valor 5 .

3. Agora, para cada respondente, some todos os valores das dez questões, e multiplique por 2.5 .

Após executar todas as etapas acima e fazer uma média com os resultados de cada respondente, o resultado final é o score SUS, um valor numérico que pode ir de 0 a 100. No caso das respostas obtidas nesse trabalho, o score SUS foi 94,75 pontos, o que é um excelente resultado. Sauro (2011) explica que o score médio é 68, ou seja, o resultado obtido nesse trabalho está bem acima da média.

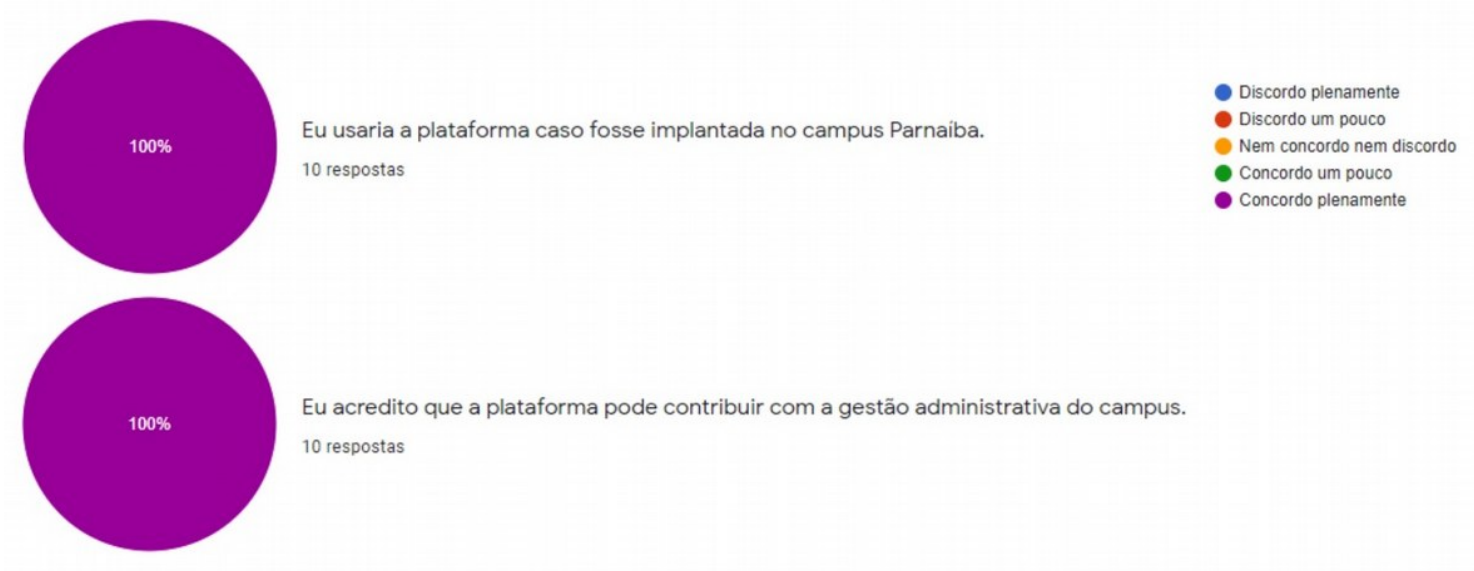

Figura 10. Respostas obtidas para as questões 11 e 12 do questionário aplicado

As questões 11 e 12 do questionário são específicas para o contexto da funcionalidade do sistema no campus Parnaíba e buscaram capturar dos respondentes, com base nos testes, o desejo de usá-lo em caso de implantação definitiva no campus. De acordo com a Figura 10, em ambas as questões todos responderam "Concordo plenamente", ou seja, um total de $100 \%$ usaria a plataforma caso fosse implantada no campus e acredita que a plataforma pode contribuir com a gestão administrativa do campus.

Em comparação com o trabalho de Funchal (2011), o sistema de reservas aqui proposto se apresenta mais robusto. No caso do sistema criado pelo autor citado, apesar dos avanços em relação ao modo como as reservas são feitas manualmente, a proposta ainda é muito simples e carece de funcionalidades essenciais como: a possibilidade de 
uma reserva ser confirmada pela administração, para casos de solicitações incoerentes; notificações para os usuários e administradores sobre atividades no sistema, sejam internos no ambiente ou por e-mail; e uma interface mais limpa e organizada. A falta da realização de testes com usuários finais também é um ponto negativo, já que não é possível atestar a qualidade do software produzido.

\section{Considerações Finais}

O objetivo desse trabalho foi propor um sistema informatizado para realização de reservas dos recursos da UESPI-Parnaíba. Alguns professores com mais tempo de serviço no campus comentavam que a demanda por esse sistema existe há muito tempo e que faltava apenas uma iniciativa. Coube aos autores desse trabalho encontrar uma forma de se projetar e desenvolver um sistema que cumprisse essa demanda.

A plataforma web projetada foi desenvolvida e testada sem grandes contratempos. A maior dificuldade foi respeitar os prazos de entrega preestabelecidos. Os usuários convidados para testar o sistema foram prestativos, dedicaram-se para explorar o sistema e sugeriram novas ideias. A metodologia SUS se encaixou bem na proposta, sendo útil para conhecer a opinião dos usuários sobre o sistema de uma forma rápida e quantitativa.

Os resultados obtidos nesse trabalho são positivos e demonstram que esta plataforma tem potencial para ser efetivamente usada como forma de substituição aos processos manuais que atualmente são realizados no campus. Como pode ser visto pelo score obtido na aplicação do questionário SUS, a plataforma atingiu um excelente nível de aceitação, estando muito acima da média para usabilidade de sistemas. Isso demonstra que o software se apresenta com uma boa interface de comunicação aos seus usuários.

Como forma de contribuir para a comunidade acadêmica, os autores disponibilizam o código-fonte do sistema de forma pública, com uso da plataforma GitLab, podendo ser acessado através do link ${ }^{1}$. A abertura do código se explica em permitir que outros estudantes e/ou desenvolvedores possam contribuir com novas funcionalidades.

Como trabalhos futuros, o desenvolvimento de novas funcionalidades pode ser estudado. A exibição de uma janela suspensa com detalhes informativos sobre o recurso e/ou ambiente motivo do pedido de reserva tornaria a experiência para o usuário mais eficaz. A substituição do campo "observação" (Figura 9) por um componente de troca de mensagens automáticas entre os solicitantes e a administração, visando facilitar o processo de avaliação dos pedidos. A criação de regras que permitam o empilhamento de novas solicitações, tornando possível a criação de pedidos com intersecção de horário.

\footnotetext{
${ }^{1}$ https://gitlab.com/tiego32/sistema-de-reservas-uespi
} 


\section{Referências}

Booch, G., Rumbaugh, J., \& Jacobson, I. (2006). UML: Guia do Usuário. Elsevier Brasil.

Brooke, J. (1995). SUS: A quick and dirty usability scale. Disponível em: $<$ https://hell.meiert.org/core/pdf/sus.pdf>. Acesso em: 19 jul. 2019.

Camões, M. R. S., Severo, W. R., \& Cavalcante, P. (2017). Inovação na gestão pública federal: 20 anos do prêmio inovação. In: Calvacante, P., Camões, M., Cunha, B., \& Severo, W. (Org): Inovação no setor público: teoria, tendências e casos no Brasil. Enap: Instituto de Pesquisa Econômica Aplicada - Ipea.

Cunha, F. W. F., Gomes, Í. S., Gonçalves, L. F., Júnior, P. R. N. O., Oliveira, R. A. S., \& Costa, S. M. F. (2017). Implementação de um sistema de trancamento de matrícula e disciplina na FATEC Carapicuíba. FATEC SEBRAE em Debate: Gestão, Tecnologias e Negócios, v. 4, n. 6, p. 96-109.

Digix. (2018). Seis exemplos incríveis de inovação no setor público. Disponível em: <http://www.digix.com.br/inovacao-no-setor-publico/>. Acesso em: 26 nov. 2018.

Django. (2017). Django: The web framework for perfectionists with deadlines. Documentation. Disponível em: <https://docs.djangoproject.com/en/1.11/>. Acesso em: 05 dez. 2019.

Funchal, L. R. (2011). Sistema web para reserva de recursos. Universidade Federal de Ouro Preto. Monografia. Disponível em: <http://www.decom.ufop.br/menotti/monoII112/files/BCC391-112-vf-06.1.4158-

LeliusReisFunchal.pdf>. Acesso em: 08 abr. 2019.

Janissek, J., Aguiar, C. V. N., Mello, T. A. B., Ferreira, R. S., \& Campos, M. S. (2017). Práticas inovadoras de gestão no contexto das universidades públicas brasileiras: validação da escala para medir seu grau de importância e adoção.

Oliveira, R. (2018). Um aplicativo online para reservas de sala: o case do CINTED/UFRGS. Universidade Federal do Rio Grande do Sul. Monografia. Disponível em: <https://www.lume.ufrgs.br/handle/10183/185080>. Acesso em: 08 abr. 2019.

Paulino, L. F. de A. L. (2017). Adoção do sistema eletrônico de informações (SEI) na Universidade de Brasília: a perspectiva dos Agentes de Mudança. Monografia.

Sauro, J. (2011). Measuring usability with the system usability scale (SUS). MeasuringU. Disponível em: <https://measuringu.com/sus/>. Acesso em: 19 jul. 2019.

Sommerville, I. (2011). Engenharia de Software. 9ª ed. Pearson Brasil. 
Teixeira, F. (2015). O que é o SUS (System Usability Scale) e como usá-lo em seu site. UX Collective BR. Disponível em: <https://brasil.uxdesign.cc/o-que-e-o-sus-systemusability-scale-e-como-usa-lo-em-seu-site-6d63224481c8>. Acesso em: $10 \mathrm{dez}$. 2018.

Vieira, E. F., \& Vieira, M. M. F. (2004). Funcionalidade burocrática nas universidades federais: conflito em tempos de mudança. RAC, v. 8, n. 2, p. 181-200. Disponível em: <http://www.scielo.br/pdf/rac/v8n2/v8n2a10.pdf>. Acesso em: 18 jul. 2019. 